\title{
SUPPORT FOR YOUTH LEAVING CARE: A NATIONAL RESEARCH STUDY, INDIA
}

\author{
Kiran Modi, Lakshmi Madhavan, Leena Prasad, \\ Gurneet Kalra, Suman Kasana, and Sanya Kapoor
}

\begin{abstract}
This paper is a condensed version of a study entitled "Beyond 18: Leaving Child Care Institutions - A Study of Aftercare Practices in Five States of India", conducted and published in 2019 by Udayan Care, a charitable organisation, with support from UNICEF India and Tata Trusts. This research involved the participation of care leavers, government functionaries, duty-bearers, and civil society practitioners. It found that upon turning 18 , youth transitioning out of child care institutions to independent life in India experience many challenges, such as securing housing and identity documents; accessing education, skill development, and employment opportunities; and garnering psychosocial support. This study also showed that absent or inadequate aftercare support during transition increases care leavers' vulnerabilities to homelessness, unemployment, substance misuse, and ruptured social relationships. It also found that continued aftercare support is necessary to foster independent living skills in these young people and enable their reintegration into mainstream society. While exploring the continuum from child care to aftercare, the researchers developed the concept of a "Sphere of Aftercare", comprising eight domains of support that are considered essential for a successful transition. The study revealed a lack of transition planning at the level of child care institutions and functionaries and a general lack of understanding of the holistic aftercare needs of youth throughout the eight identified domains. The study also found an absence of clarity about stakeholders' roles; a lack of data management with regard to the number of youth leaving care, leading to inadequate budget planning; and a lack of adequate monitoring mechanisms to assess care leavers' outcomes. In light of this study's findings, policy reforms and ways of developing robust aftercare programmes are recommended in relation to policy, practice, and law.
\end{abstract}

Keywords: aftercare, care leaver, India, transition, youth

Acknowledgement: Permission to reprint this material has been granted by Dr. Kiran Modi, the corresponding author. We gratefully acknowledge this permission. 
International Journal of Child, Youth and Family Studies (2020) 11(4.2): 160-187

Kiran Modi PhD (corresponding author) is the Founder and Managing Trustee of Udayan Care, A-43, Chittaranjan Park, New Delhi - 110019, India. Email: kiranmodi@udayancare.org

Lakshmi Madhavan MA is a Project Officer at The National Institute of Mental Health and Neuro-Sciences, Hosur Road, Bengaluru - 56002, Karnataka, India.

Email: lakshmimadhavan@live.com

Leena Prasad LLB is the Assistant Director (Advocacy, Research, Training) at Udayan Care, A-43, Chittaranjan Park, New Delhi - 110019, India. Email: leenadivansh@gmail.com

Gurneet Kalra PhD is Senior Coordinator (Research and Advocacy) at Udayan Care, A-43, Chittaranjan Park, New Delhi - 110019, India. Email: gurneet.kalra89@gmail.com

Suman Kasana BA is pursuing a Masters in Public Policy from the National Law School of India University, Bengaluru, Karnataka, India. Email: smnkasana@gmail.com

Sanya Kapoor is a final year law student at Amity Law School, F-1 Block, Amity University Campus, Sector 125, Noida, Uttar Pradesh 201303, Delhi, India.

Email: sanyakapoor2809@gmail.com 
It is indisputable that a safe and functional family is the keystone for ensuring a child's optimum development and harmonisation with society at large. The United Nations Convention on the Rights of the Child (UNCRC; 1989), which has been ratified by the Government of India, recommends that every effort be made to avoid separation of children from their parents until separation is clearly in the best interest of the individual child (Article 9). Additionally, the United Nations Guidelines for the Alternative Care of Children (UNGACC; 2009) has prescribed two guiding principles for children living in any alternative setting: the "principle of necessity" and the "principle of suitability"; these attempt to ensure that only those children who absolutely need alternative forms of care are considered for and placed in alternative care contexts, and that those contexts are the most suitable to their healthy and holistic growth and development (United Nations General Assembly, 2009).

In India, as in many other countries, owing to numerous circumstances such as parental death, poverty, abuse, disasters, and armed or internal conflicts, children are separated from their birth families and are often forced to grow up in alternative care settings meant for children without parental care, where they become the responsibility of the state.

The key instruments governing child care and aftercare in India are the Juvenile Justice (Care and Protection of Children) Act 2015, its Model Rules 2016, and the Revised Integrated Child Protection Scheme (CPS; Ministry of Women and Child Development, 2014), which together provide an overarching legal framework for child care and aftercare support for children in need of care and protection in alternative care settings as well as for children in conflict with law. In the Indian scenario, in the absence of robust foster care and other family-based care models, child care institutions (CCIs) remain the most sought-after option for the care and protection of children without parental care. The term "CCI", as mentioned in The Juvenile Justice (Care and Protection of Children) Act (2015), can include any of the following: "Children Home, open shelter, observation home, special home, place of safety, specialised Adoption agency, and a fit facility, recognised under this Act, for providing care and protection to children, who are in need of such services", on a short-term or long-term basis. CCIs are intended to address the overall needs of targeted children in an age-appropriate manner (Udayan Care, 2017).

Aftercare is provided to a young person who exits formal care at 18 years of age and who is then called a care leaver (CL). He or she has transitioned out of child care to start the journey towards independent living and social integration, and for whom a comprehensive set of services across different domains of life must be provided. It is pertinent to note here that, for children growing up and residing in CCIs up to the age of 18, a robust ecosystem to support them in the aftercare phase is lacking, despite pronounced laws on the kind of aftercare support they should be getting (Dabir et al., 2011). The transition from protected living as a child in a CCI to independent living as an adult requires substantial support in the form of aftercare to enable selfreliance. Aftercare, as a vital component of the continuum of care, is crucial for CLs if they are to 
realise their true potential and become contributing members of society. Due to lack of adequate preparation and requisite transition planning at the CCIs, and non-implementation of the aftercare programme, these youth are usually among the most socially excluded and vulnerable people in society (Dutta, 2017).

This paper is an attempt to capture the situation of CLs and aftercare approaches as they currently exist in India; to highlight the gaps in policy, law, and practice on aftercare; and to suggest a workable pathway forward. Globally, many studies describe the challenges of children in institutions, the struggles of transition to independent life, and the transition's impact on CLs (Akister et al., 2010; Doucet, 2018; Meade \& Mendes, 2014). Unfortunately, in India, one cannot find much empirical evidence regarding those challenges and struggles. Only a few standalone studies, from districts, states, and facilities, have been conducted, most of them are qualitative in nature; furthermore, most studies do not explore the multiple dimensions of aftercare (Atluri et al., 2018; Dutta, 2016).

Our intensive research in several states revealed that there is a clear lack of documentation on aftercare in India; on this basis, Udayan Care initiated a study on aftercare in collaboration with UNICEF and Tata Trusts that aimed to build empirical evidence with a view to influencing the practice of aftercare and improve outcomes of CLs in India. The research was titled, "Beyond 18: Leaving Child Care Institutions - A Study of Aftercare Practices in Five States of India." This report explained the conditions and experiences of children and aftercare youth in India. It also highlighted some recommendations made by different stakeholders themselves, and attempted to capture conditions and circumstances faced by CLs and existing aftercare approaches in order to highlight the existing gaps in aftercare policy, law, and practice and suggest a workable pathway forward. It also places a strong emphasis on the need for collaborative and coordinated efforts between different stakeholders to ensure no CL is left behind.

In its conception, the Beyond 18 study kept in view three interrelated dynamics: the critically important nature of aftercare services for the rehabilitation of CLs; the inadequate availability of aftercare infrastructure and support in certain Indian states; and the nearly total absence of empirical data regarding their annual numbers, leading to inadequate budget planning, as well as difficulty understanding the nature of challenges and opportunities faced by young adults in need of aftercare support. This was based on our literature review, where studies stated the lack of infrastructure and support for the CLs (Rutman \& Hubberstey, 2016), the importance of rehabilitative services for CLs (Trout et al., 2014), and the absence of enough evidence regarding the challenges being faced by the CLs (Murray \& Goddard, 2014). This research brought together a much bigger universe of CLs and stakeholders from five different states of India, than did earlier Indian studies, and also generated both qualitative and quantitative evidence on multiple aspects of aftercare. 


\section{Literature Review: The Transition from Child Care to Aftercare and then the Larger World}

A gradual and supported transition out of alternative care settings is the key to ensure that young adults "aging out" of the system prosper in their lives as they move forward (Modi et al., 2018). This transition, if not adequately planned and implemented, is bound to bring about a host of difficulties. The transition to aftercare and then independence requires youth to have emotional stability, functional skills, and financial independence (Montgomery et al., 2006). However, a lack of positive adult interaction from consistent carers limits CLs' ability to develop personal confidence and key social skills (Modi et al., 2016). There is also definitive research showing that the basic tenets of education are compromised in the CCIs, leading to negative impacts on students' educational progress and related developmental outcomes (Browne, 2017; Legal Center for Foster Care and Education, 2008). Further, poor academic performance leads in the long run to outcomes such as unemployment and low wages, making it difficult for young people to earn a decent livelihood (Torrico, 2010; United Nations World Youth Report, 2020).

Studies of the mental health of CLs have consistently shown that self-stigma and social stigma impact their access to mental health services (Villagrana et al., 2017). It has also been found that self-stigma affects an adolescent's self-identity, self-efficacy, and interpersonal relationships. This influences self-sufficiency once youth leave care (Villagrana et al., 2017). Therefore, support in the forms of free counselling, guidance, interventional support, psychological assessment services, and crisis management support from designated mental health professionals has been recognised as vital to successful transitions (Gutterswijk et al., 2020). CLs also need constant guidance in developing life skills, knowledge about their legal rights and responsibilities, and training on how they can nurture their own personal development through self-care and prosocial behaviour (Browne, 2017). Analysis of the aforementioned studies shows that aftercare is an important final stage in the continuum of care, as it ensures smooth rehabilitation and reintegration of children in need of care and protection and of children in conflict with the law as they step into adulthood (Doucet, 2018).

\section{Policy and Legal Framework for Aftercare}

\section{International framework}

UNGACC provides comprehensive guidance on minimum standards for aftercare services (UNGACC, 2009). It urges agencies and facilities to have a clear policy aimed at preparing children and youth to be self-reliant and to acquire social and life skills by giving them educational and vocational training opportunities, and access to social, legal, and health services, along with financial support. It also expects the agencies to take into consideration a youth's gender, age, and maturity; to provide counselling and support throughout the process of transition from care to aftercare - notably to avoid exploitation; and to encourage the public and private sectors to employ such youth by providing the necessary incentives (Mori et al., 2018). 
International Journal of Child, Youth and Family Studies (2020) 11(4.2): 160-187

\section{National policy framework}

The Constitution of India and various laws and policies laid down over the years have reiterated the Government's commitment to safeguarding the rights of children. The National Policy for Children, 2013 refers to "child protection" as one of its priorities and recognises vulnerable categories of children who are in need of intervention. However, the national policy does not explicitly recognise the vulnerabilities of children leaving CCIs and the need for aftercare (Ministry of Women and Child Development, 2013).

Later, the National Policy for Youth 2014 was developed, which specifically recognised that, "There are a number of youth at-risk and marginalised youth who require special attention in order to ensure that they can access and benefit from the government programmes" (Ministry of Youth Affairs \& Sports, 2014, p. 66). It also acknowledged "youth in institutional care, orphanages, correctional homes and prisons" as a vulnerable group, but none of the policies specifically addressed the needs of CLs (Ministry of Youth Affairs \& Sports, 2014, p. 67).

To link the policy objectives to actionable programmes, the National Plan of Action for Children (NPA) was formulated in 2016. It prioritised "providing adequate and appropriate infrastructure and ensure safety and security of children in all residential care facilities ... established under domestic laws" (Ministry of Women and Child Development, 2016, p. 12). However, the NPA also did not make any specific reference to children leaving institutions on attaining majority.

The National Policy for on Skill Development and Entrepreneurship 2015, (Ministry of Skill Development and Entrepreneurship, 2015) aims to meet the challenge of skilling training at scale with speed, standard (quality), and sustainability, and provides an umbrella framework to for skill development. Additionally, there are schemes initiated by the government that provide subsidies

and scholarships for higher education, all of which can be accessed by the CLs (National Policy for on Skill Development and Entrepreneurship, 2015, pp. 29, 32).

\section{National legislative framework}

Juvenile Justice (Care and Protection of Children) Act, 2015 and Model Rules, 2016: In the Juvenile Justice (Care and Protection of Children) Act 2015 (JJ Act), Section 2(5) stipulates that, " 'aftercare' means making provision of support, financial or otherwise, to persons, who have completed the age of eighteen years but have not completed the age of twenty-one years, and have left any institutional care to join the mainstream of the society" (p. 2). Further, Section 46 urges the state to provide financial support to children leaving a CCI at 18 years of age "in order to facilitate child's re-integration into the mainstream of society" (p. 24). The procedures and processes are further defined in the Juvenile Justice (Care and Protection of Children) Model Rules 2016 (JJ Rules), which are more operational in nature. They state that children leaving institutional care at the age of 18 "may be provided aftercare till the age of $21 \ldots$ and in exceptional circumstances, for two more years on completing 21 years of age" (p. 196). State governments 
must make an aftercare programme and provide funds for children in aftercare, which must be transferred directly to their bank accounts (p. 195). Services to be provided under the aftercare programme are clearly defined.

Child Protection Scheme: The CPS that came into effect in 2009 and was revised in 2014 (Ministry of Women and Child Development, 2014) is the vehicle for financing and implementing the JJ Act. The scheme outlines the criteria for the selection of aftercare organisations and the delivery of aftercare services. Under this scheme, aftercare is rudimentarily funded through the aftercare organisation at the meagre monthly sum of Rs. 2000 (27.40 USD) per transitioning youth. Under the CPS, the budgetary support that states can seek for aftercare programmes ranges from Rs. 15 lakhs (20,560 USD) for states with less than 15 districts, to Rs. 45 lakhs (61,663 USD) for states with more than 30 districts (Ministry of Women and Child Development, 2014, p. 55).

Child protection machinery and roles: In India, Child Welfare Committees (CWCs), Juvenile Justice Boards, or the Children's Courts can order a youth to receive aftercare from the ages of 18 to 21 years or, if required, 23. They are also mandated to review the effectiveness of the aftercare support extended and monitor the progress of every youth. The State Child Protection Society (SCPS) is responsible for developing programmes for aftercare and maintaining a database of aftercare organisations. The District Child Protection Unit (DCPU), which has primary responsibility for the implementation of the CPS in each district, develops aftercare-related databases and referral directories at the district level to share with the SCPS.

Planning for transition and rehabilitation: Section 39(1) of the JJ Act, 2015 refers to the child's individual care plan (ICP) as the basis for the rehabilitation and social integration of any child who is being released from an institution, irrespective of their age. The ICP is defined in the JJ Rules, 2016 (p. 176) and includes components of release and restoration, follow-up, and social mainstreaming. The ICP has a component on a pre-release report, to be prepared 15 days before release, that includes the rehabilitation and restoration plan for the youth (p. 263). It also has a post-release plan but with a focus on restoration to families (p. 264).

Services: The services provided under the aftercare programme (as provided by CPS and JJ Rules, 2016) may include:

community group housing on a temporary basis ...; provision of a stipend during ... vocational training or scholarships for higher education ...; arrangements for skill training, and placement ... through coordination with National Skill Development Programme, Indian Institute for Skill Training and other such ... programmes; provision of a counsellor to stay in regular contact ... to discuss their rehabilitation plan; provision of creative outlets ...; arrangement of loans and subsidies for [those] aspiring to set up entrepreneurial activities; and encouragement to sustain themselves without State or institutional support. (p. 195) 
Also, CLs are encouraged to move out of the group home to stay in a place of their own. Moreover, Rule 83(4) allows the Juvenile Justice Fund to be used for providing lump-sum subsistence support to CLs. It can also be used for providing aftercare facilities and entrepreneurship funds to CLs for starting up small businesses.

Whilst policy and law clearly recognise the need for aftercare through a range of services, the lack of systematic preparation for aftercare, the paucity of resources, the low number of functioning aftercare organisations across the districts, and a lack of understanding of roles and responsibilities amongst functionaries result in a situation where very few of these services actually reach CLs (Dutta, 2017).

\section{Research Methodology}

Children exiting CCIs on attaining adulthood need extended support in the form of aftercare. Thus, study of the present ecosystem of aftercare practices is crucial, not only to develop an understanding of the CLs' situation, but also to develop strategies to support youth leaving care (Bhargava et al., 2018). To this end, Udayan Care's national aftercare study researched the current aftercare practices in the states of Delhi, Gujarat, Karnataka, Maharashtra, and Rajasthan. This study considered the three interrelated aspects of aftercare: the nature of aftercare services for rehabilitation of CLs, the inadequate availability of aftercare support and infrastructure, and the lack of data regarding challenges faced by these CLs.

\section{Design}

The present study followed a mixed method approach with a descriptive research design that uses both the quantitative and qualitative methods of inquiry in tandem.

\section{Participants’ Demographics}

Table 1 provides an overview of how many CLs in each state participated, when the research was conducted, and how many key informant interviews (KIIs) took place in each state.

Table 1. Research Overview

\begin{tabular}{lcll}
\hline State & Total CLs & Period of research & KIIs \\
\hline Delhi & 55 & February-April 2019 & 10 \\
Gujarat & 84 & November 2018-May 2019 & 20 \\
Karnataka & 108 & April-December 2018 & 14 \\
Maharashtra & 107 & April-October 2018 & 20 \\
Rajasthan & 81 & September 2018-April 2019 & 20 \\
\hline
\end{tabular}

Note. $\mathrm{CL}=$ care leaver; $\mathrm{KII}=$ key informant interview. 
International Journal of Child, Youth and Family Studies (2020) 11(4.2): 160-187

\section{Care Leavers}

Participants in the Beyond 18 study were children in need of care and protection who had attained the age of 18 years and had exited a CCI in one of the five states under study. A total of $435 \mathrm{CLs}$ who had grown up in a CCI and were older than 18 years of age were contacted. A stratified convenience sampling method was used for conducting the interviews, based on the CL's age, sex, and type of CCI (government or non-government). The process of selection of respondents involved the following steps:

Step 1: The research team approached governmental and non-governmental organisations (NGOs) engaged in aftercare and child care services, as well as the local DCPU and CWC members, to obtain names and contact details of young adults who fulfilled the criteria noted above.

Step 2: Respondents were stratified based on their age (18-21 years, 22-25 years, and 26 years and above), their sex/gender, and the type of CCI they had lived in (governmental or NGO) with an aim to have proportionate representation wherever possible. The sample comprised $55 \%$ male CLs and $45 \%$ female CLs. There was a state-wise variation in the gender composition, with Maharashtra having a significantly higher representation of males. All the CLs within the ambit of this study were between the ages of 17 years and 30 years, with $72 \%$ in the age group of 18 to 21 years; only one CL was 17 years of age. A little less than half of the CLs had resided in government-run CCIs. Those CLs who had received aftercare service or support on one or more occasions from a state government or an NGO-run aftercare programme were designated "aftercare receivers".

\section{Key Informants}

For a more complete understanding of aftercare in the state, along with CLs, the research team brought together a sample of 84 key informants (KIs), both male and female. As it was important to look for a wide variety of viewpoints and experience, KIs included representatives of various CCIs (governmental and non-governmental), aftercare providers and programme managers, social workers, case workers, practitioners, experts, policy-makers, activists, and scholars in child and youth protection. Another set of perspectives was provided by state officials: representatives of the Department of Social Justice and Empowerment and of the Department of Women and Child Development, CWC members, Juvenile Justice Board members, District Child Protection officers, State Child Protection officers, District Women and Child Development officers, Child Welfare officers, and probation officers.

\section{Data Collation and Collection}

The study used a diverse set of tools for data collation, indigenously developed, with an interwoven mechanism of triangulation for better understanding of the lives of the CLs and the views of the stakeholders engaged in aftercare. An inception consultation was held at the initial stage of the research in each state to develop an understanding of the situation and collate 
secondary data. These workshops provided information that was critical in adapting the research to each state. This was also used as an opportunity to conduct three focus group discussions (FGDs) in each state. Round-table meetings with stakeholders were organised again in each state towards the end of the study, to share the draft findings of the study and seek input on the recommendations.

Certain other tools, such as structured interviews of CLs, in-depth interviews for case studies, and semi-structured and open-ended KIIs, were also used extensively. The tools were finalised, and content validated during the pilot-testing phase by a team of researchers, analysts, statisticians, and experts from the field. Data collection was completed by the state documentation teams through individual in-person interviews in different locations such as coffee shops, their places of accommodation, and public parks. Table 2 below provides an overview of the tools employed for data collection.

Table 2. Tools Employed for Data Collection

\begin{tabular}{lll}
\hline Tool & Stakeholder & Description \\
\hline Structured & CLs & This interview schedule was developed by Udayan Care's multidisciplinary \\
interviews & & team of experienced practitioners with inputs from UNICEF state teams and \\
& state implementation partners, and international and Indian research scholars \\
& specialising in aftercare research. The probes were crafted keeping in mind the \\
& sensitivities of the CLs. Questions with the potential of triggering any negative \\
& emotions were reworded or removed.
\end{tabular}

In-depth $\quad$ In-depth interviews were designed covering areas pertinent to CLs including interviews for separation, trauma, neglect, life in CCIs, opportunities and challenges in their case studies present lives, and their perceived success or failure.

The CLs chosen for case studies included young adults in different life situations: successful, moderately successful, or struggling. Semi-structured interviews were conducted. To analyse the case studies, Mike Stein's categories of "moving on", "survivors", and "strugglers" were used (Stein, 2012).

Semi-structured KIs Semi-structured interviews were used to elicit candid responses from these and open-ended professionals regarding their opinions of the existing aftercare framework. The interviews KIIs were administered in-person, by email, or by phone.

Focus group

discussions

The FGD guide was developed for CLs and with KIs. The proceedings of the FGDs consolidated the research team's understanding of the complex and interdependent challenges of aftercare provision.

Note . $\mathrm{CCI}=$ child care institution; $\mathrm{CL}=$ care leaver; $\mathrm{KI}=$ key informant; $\mathrm{FGD}=$ focus group discussion.

\section{Ethical Approval and Limitations}

The research protocol, along with the current study's design, methodology, and tools, were approved by the Suraksha Independent Ethics Committee through its Committee for Scientific Review and Evaluation of Biomedical Research. This research does present certain limitations, such as inability to access CLs who did not receive any aftercare support, inability to sample CLs 
from rural locations, non-inclusion of CLs with special needs, and lack of available documentation in the public domain.

\section{Sphere of Aftercare — The Study Framework}

The research team undertook a secondary review of various frameworks for delivering aftercare in other countries. Combining these existing frameworks with our practice-based understanding, developed through Udayan Care's years of experience in dealing with aftercare, and the pilot study in Delhi, the team evolved a framework for approaching aftercare comprehensively: the "Sphere of Aftercare" (see Figure 1). This is a comprehensive set of principles relating to rehabilitative support and services for CLs transitioning out of care. The Sphere of Aftercare framework divides the scope of aftercare support and services into eight interdependent domains in which CLs may require support if they are to successfully transition out of care into mainstream society: housing, independent living skills, physical health, educational and vocational skills, social support and interpersonal skills, financial independence and career, emotional well-being, and identity and legal awareness. Since each state is unique in its policy approach and the present state of aftercare varies, the study does not attempt to consolidate data. Instead, the focus is to bring out common trends that indicate where learning is needed or where a gap needs to be filled. It also brings forth the outliers or the deviations in specific states that call for more concerted intervention.

Figure 1. The Sphere of Aftercare

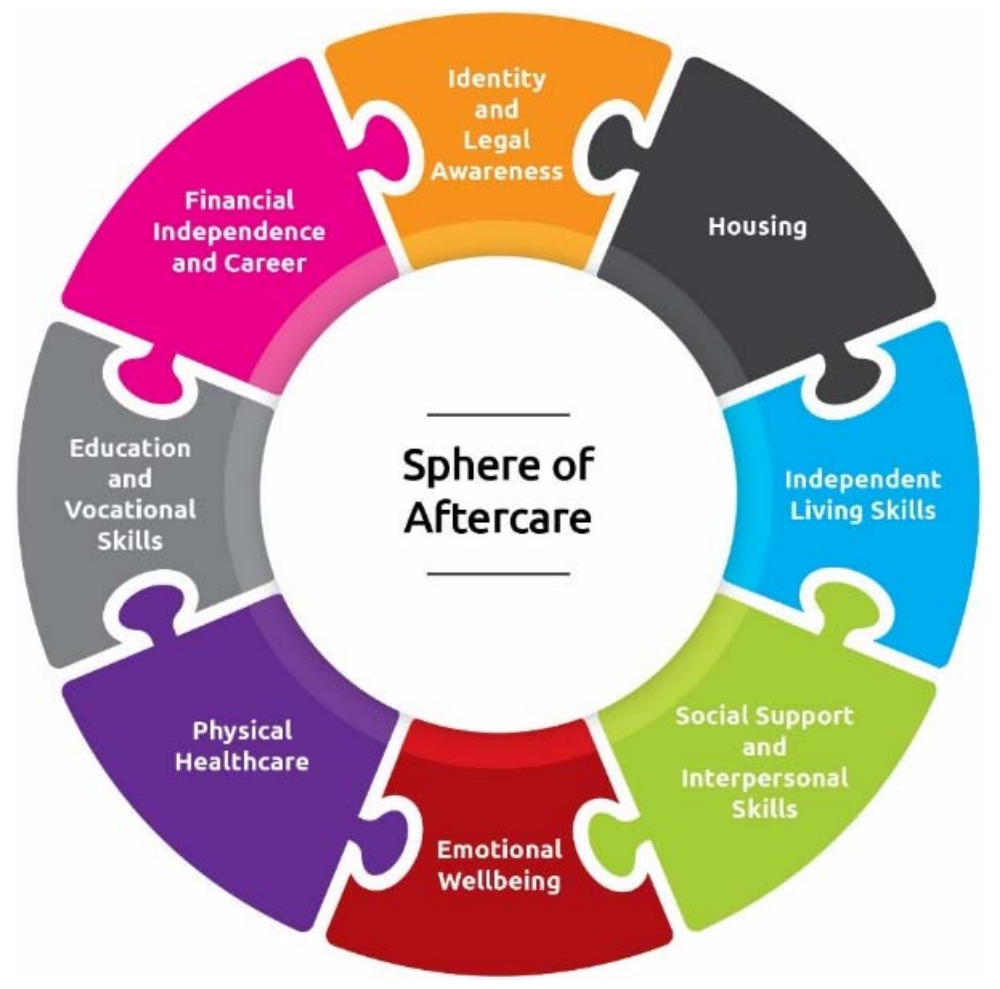


International Journal of Child, Youth and Family Studies (2020) 11(4.2): 160-187

It is posited that if a CL is to achieve independence and social reintegration, none of these domains can be ignored. As CLs transition out of care, they may require support and services under one or more of these domains depending on their unique needs and aspirations. The Sphere can serve as the guiding principle for assessing CLs' needs and developing aftercare programmes. The Sphere of Aftercare framework was used in the construction of interviews and questionnaires; the resulting data were then subjected to qualitative analysis. Additional themes were identified based on conventional methods of qualitative analysis. Quantitative data was processed with the help of the Statistical Package for Social Sciences (SPSS). Descriptive statistics, frequencies, and crosstabulations were used for analysing the data. Thereafter, tables, charts, and graphs were prepared.

\section{Indexing}

A composite score for each of the eight domains was computed to develop a domain index. Each of these eight domain indices consisted of anywhere between three to 18 polar questions that could be answered either "yes" or "no". A positive answer was assigned a score of 1, while a negative answer was assigned a score of 0 . A respondent's domain index score was the average score for the selected questions. Depending on their domain index score, each CL was categorised as having an "unsatisfactory", "neutral", or "satisfactory" score for that domain. Further analyses and correlations were conducted on the domain index scores and their categorisation. The scores for each of the eight domains were added and averaged out to give the overall aftercare quality index (AQI) for each CL. Additionally, two more indices were developed for the transition planning phase that precedes aftercare and is the preparatory period at CCI before transitioning. These two indices capture the childhood experiences and skill development of CLs before leaving the CCI at 18 years.

\section{Results and Discussion}

With the objective of understanding the status of aftercare in India, this study was conducted across the five states of Delhi, Gujarat, Karnataka, Maharashtra, and Rajasthan. Each of these states is unique not only from the perspective of its overall policy framework but also with respect to the status of the state's implementation of the JJ Act, the institutional care services it provides, its history of aftercare services, and its further initiatives to design and deliver aftercare services to CLs. Further exploration of this topic is not within the scope of this paper; interested readers are referred to the main report ${ }^{1}$ (Udayan Care, 2019).

The major finding of the study shows that upon leaving their CCIs at 18 years, and faced with living independently in the outside world, many of our participants did not receive adequate aftercare support and struggled to adjust to the transition. The study findings also indicate that 59\% of CLs were not aware of aftercare services and other welfare schemes that they could have accessed. The analysis of access to aftercare and welfare services further revealed that, while

\footnotetext{
${ }^{1}$ https://www.udayancare.org/research-and-publication/research-studies-and-papers
} 
International Journal of Child, Youth and Family Studies (2020) 11(4.2): 160-187

around $73 \%$ of all CLs received aftercare services in at least one of the domains of the Sphere of Aftercare, more than a quarter $(27 \%)$ of the CLs did not receive any form of aftercare support.

The following section reports on the quantitative findings from interviews with 435 CLs from the five states, as well as the qualitative data obtained through 84 KIIs with different stakeholders, 12 FGDs and 23 in-depth case studies across the five states.

\section{Life in CCI}

To explore the life of the CLs in the CCIs, two indices, the CCIs Life Experience index and the Skill Development index, were considered. The CCI Life Experience index is a composite score that factors continuity of education, association with family, stability or instability through multiple placements, and feelings of empowerment, as well as involvement in the planning of one's future life. Overall, only half (51.5\%) of all CLs had a satisfactory CCI Life Experience index score, with $58 \%$ of CLs from NGO-run CCIs, but only $45 \%$ of CLs from Government-run CCIs, reporting a satisfactory score. Additionally, we found that the CCI Life Experience index was positively correlated to all eight domains in the Sphere of Aftercare. Therefore, we show that children who have had positive experiences in the CCIs are likely to fare better in most domains of aftercare.

A composite CCI Skill index score for three groups of skills - job readiness and vocational skills, independent living skills, and interpersonal skills - was computed, based on whether children in CCIs received any training, either hands-on or through workshops. About 37\% of CLs had an "unsatisfactory" CCI Skill index score, indicating that CLs gained only minimal skill training during their stay in the CCI. Karnataka had the best score for skill training as only $43 \%$ of the CLs had an unsatisfactory score, whereas Rajasthan had the worst score with $99 \%$ of the CLs reporting an unsatisfactory score.

An analysis of the findings in regard to the Sphere of Aftercare shows that while the CCIs are intended to serve as a refuge to protect the CLs, they fail to prepare them to establish links with society by harmonising their needs and wants with the rest of society, as opportunities for exposure are limited. More than three-quarters of the CLs left the CCIs before the age of 20, while 17.5\% stayed beyond that age. CLs living in the CCI after the age of 18 years included $28 \%(n=98)$ of the respondents from Rajasthan and 30\% $(n=84)$ of those from Gujarat. In Delhi, 51\% of the CLs left their CCI at 19 years. Extended stays in the CCIs are authorised by the CWCs; in most cases, they are allowed because the youth were still pursuing school education, and a change in residence was deemed not to be in their best interest.

A majority of our participating CLs had been placed in more than two CCIs during their stay in care. CLs stated that this instability had not only disrupted their education but also hampered the process of relationship building with peers and CCI staff. 
International Journal of Child, Youth and Family Studies (2020) 11(4.2): 160-187

\section{Housing}

The first and foremost area in need of attention for youth who are leaving care is housing, without which CLs will be unable to establish themselves as independent adults in society (Trout et al., 2010). Aftercare services and support are envisioned in law as a form of non-institutional care, but have largely been implemented as a form of institutional care. This experience of remaining institutionalised post-care can be understood through the words of one of our participating KIs, who told us that:

Aftercare as per JJ Act is a programme but it has been implemented as an institution and that is opposed to the concept of aftercare programme. Living together in groups, doing everything on their own, managing daily chores, and to have a mentor just for guidance will make them independent. Living in a structure or in organisations which are closed door, a youth cannot learn. How do you expect a bird to learn to fly in a cage?

Less than half of all the respondents across states received housing support under aftercare. From the perspective of overall aftercare services received, only $61 \%$ of all aftercare receivers received housing support. The proportion of aftercare receivers (88\%) with a "Satisfactory Housing index" was higher than the non-receivers $(75 \%)$, reinforcing that aftercare services are helpful in the transition and adjustment of CLs to adult life.

The stakeholders participating in the study suggested that non-institutional housing is key to both the integration of CLs into society and the development of their independent living skills, and that institutional aftercare facilities can serve only as a midpoint for the CLs to transition to independent life. Using independent group homes that have shown promise as a model and formalising similar practice into policy is supported by most stakeholders. The current JJ Act and Rules do not provide any mechanisms for according recognition to NGO-managed aftercare homes. However, the stakeholders shared that stigma and insensitivity among citizens make it difficult to establish group homes and obtain rental housing. Besides this, there are no guidelines for semi-regulated accommodation and group housing.

The gender disparity that exists in the provision of housing facilities for CLs also requires attention. There are presently only two aftercare homes for girls, one each in Delhi and Maharashtra. The female CLs in the other states had nowhere to turn except temporary shelters built for the homeless, or "Swadhar Greh", which are homes for destitute girls. This is an eyeopener for all of us as the situation is grave and calls for provisioning of temporary housing support options for those CLs struggling with housing.

\footnotetext{
${ }^{2}$ The Indian government website explains that, "The Ministry of Women and Child Development is implementing the Swadhar Greh Scheme which targets the women victims of difficult circumstances who are in need of institutional support... The Scheme envisages providing shelter, food, clothing and health as well as economic and social security for these women.” https://www.india.gov.in/spotlight/swadhar-greh-scheme
} 


\section{Independent Living Skills}

As international studies have stated, starting to live independently is a challenge for any young person and a considerably bigger challenge for CLs who have had a constrained life in the controlled setting of a CCI and have little or no family support (Everson-Hock et al., 2011). Andrea (2018) observed that young people who have received long-term group care in residential homes have significant difficulties when it comes to independent living. Insufficient preparation for this transition has been proven to be detrimental to CLs' future possibilities. Stepping out from the comfort zone of the CCI to the world requires independent living skills. The importance of these skills is captured here in the words of a stakeholder:

We should start by the age of 12-13 years to train children in basic activities of daily living. Maintaining their own hygiene, cleaning their rooms, managing expenditure on grocery, and using public transport, etc. Early learning and socialisation will make them confident to manage life outside CCIs.

Skills deemed important for the CLs are: nutrition and health, cooking, first aid, disaster management, household management (taking care of belongings, hygiene, and financial management), and exercise and recreation. The Independent Living Skills index was calculated by considering whether CLs had acquired these skills, either through training or hands-on experience. However, we found that the participants in our study appeared to have experienced a deficit in the development of independent living skills as part of the transition planning. Our study revealed that two out of every three CLs were unprepared with respect to independent living skills as evidenced by their unsatisfactory Independent Living scores.

Table 3. Independent Living Skills Scores

\begin{tabular}{lrr}
\hline Score & $n$ & $\%$ \\
\hline Unsatisfactory & 73 & 66 \\
Neutral & 93 & 8 \\
Satisfactory & 43 & 26 \\
Total & 435 & 100 \\
\hline
\end{tabular}

For example, three out of five CLs had not acquired cooking and household management skills. It was also found that gender had an impact on the amount of independent living skills training received, including through aftercare services, with about $14 \%$ more female CLs reporting having received such training than male CLs, both while in CCI and after leaving. We believe that these findings are indicative of stereotypes related to gender roles, wherein cooking and household management are assumed to be a female's role. Commenting on this, one of the CLs stated:

As an idea it (aftercare) is very good, as it provides the boys who do not have any support a place to stay, and also an opportunity to work towards their own settlement. But there is very little guidance. At present, the staff are the sole 
decision makers, and the inputs of the boys are not considered. I don't have any large expectations. They must consider us as important and they must have faith in us, that we can do anything and everything as per the decisions pertaining to our life.

CLs in Karnataka fared better, with more than 50\% rated satisfactory on the Independent Living Skills index. This could be because a substantial number of children living in CCIs in Karnataka had families and were placed in the CCI to improve their educational prospects. The regular access of these children to family environments may have boosted their independent living skills. It was also understood from the findings that the CLs were not allowed to make decisions for themselves during their stay in the CCI, depriving them of the chance to acquire independent living skills.

\section{Social Support and Interpersonal Skills}

Children without parental care and residing in institutional care for most of their childhood have limited exposure to the larger community, which deprives them of opportunities to build social and interpersonal skills (Modi et al., 2016). Children in CCIs are not accustomed to family relationships and it is therefore important that they enjoy long-term relationships with caregivers, which is not possible when their stay in CCI includes multiple placements. The development of social relationships and interpersonal skills becomes extremely important for CLs in their transition towards becoming active members of society, yet almost half of the CLs faced an inability to maintain relations with parents (if there were any), and more than $40 \%$ of the CLs requested training on basic social skills. The Social Support index was calculated by factoring in the various relationships that CLs were able to maintain and whether they had acquired certain interpersonal skills such as: conflict resolution; effective communication; leadership, trust, and team building; an understanding of legal rights, responsibilities, and moral duties; ego-resiliency and self-esteem; and gender neutrality and inclusion. Unfortunately, 46.7\% of all CLs had an unsatisfactory score on the Social Support and Interpersonal Skill index. Figure 2 provides an overview of the level of aftercare support received by the CLs.

Figure 2. Level of Aftercare Support Received by CLs

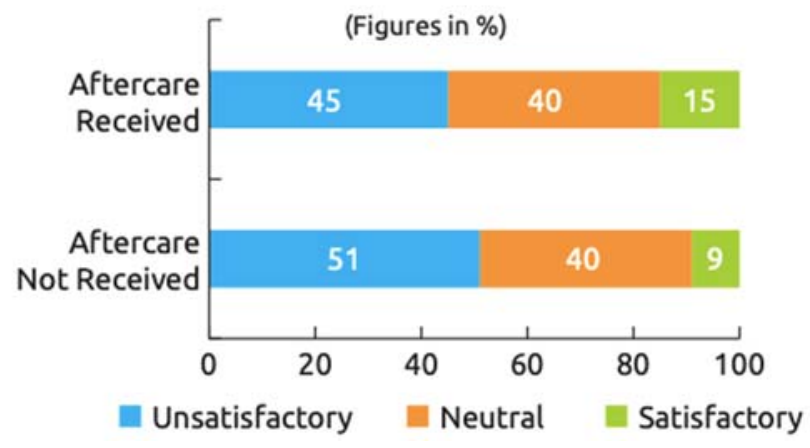


One of the CLs stated that, "People outside don't really understand us, and we too don't trust the people outside." A need for peer social-support networks, access to information and services, and for opportunities to socialise and celebrate together was clearly visible in our findings. Figure 3 provides an outline of the social skills training received by the CLs in CCIs and after leaving CCIs.

Figure 3. Social Skills Training Received

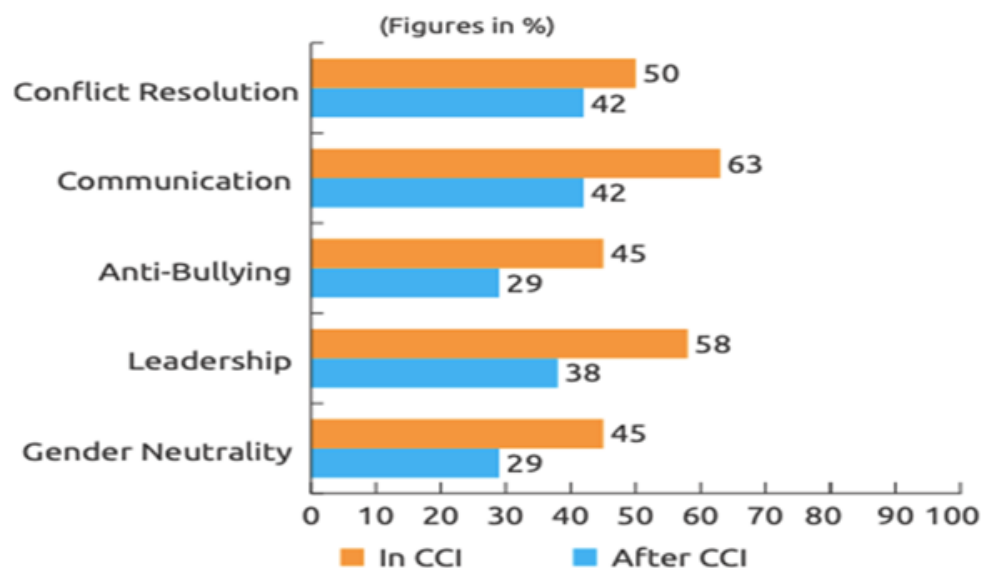

Care leavers networks: The CLs experienced stigma from society, and this discouraged them from connecting with people in their neighbourhoods, colleges, and workplaces. Besides this, the CCIs were often disconnected from the community, and thus unable to interact with it. With this in mind, the stakeholders highlighted the importance of peer social-support networks, access to information and services, and opportunities to socialise and celebrate together. Forming such groups could provide safe spaces for CLs to discuss their issues, and they could act as selfadvocacy groups.

Mentorships: Our findings also suggested that CLs could gain social exposure and better integration with the community through mentorship by individuals and by collaborating with professionals and corporations. This would help in facilitating their access to a wider community and subsequently engender mutual acceptance by both sides. One of the stakeholders plainly stated this need for mentorship: "Since the youth has not lived in a family, how would they understand the concept of familial or romantic relationships? For a happy married life, they require proper pre-marriage counselling, where mentors can really counsel and guide them."

\section{Physical Health and Emotional Well-being}

A study conducted by University of Maryland, Baltimore, revealed that many CLs are reduced to homelessness or living in poor, unhygienic environments upon departure from their child care home or foster home (Barth, 1990; Center for Evidence-Based Management, 2014). We have found a similar phenomenon in Indian settings when the CLs have to secure an accommodation 
within a limited budget: to maintain the upkeep of their hard-won accommodation is an additional source of stress in their lives. As a result, CLs' risk of experiencing problems with physical health is quite high. The physical health and emotional well-being of the CLs, though often neglected by practitioners, were significant domains of aftercare in our current study. The components of physical health include access to health care, availability of caregivers, access to funds for treatment, and coverage under health insurance schemes. Some of the major findings with respect to the physical health of CLs are that $23 \%$ of CLs did not receive long-term caregiving during illnesses, and that $78 \%$ of CLs did not have health insurance. Moreover, the study revealed that $86 \%$ of CLs in Delhi, $63 \%$ in Rajasthan, and 54\% in Gujarat faced emotional distress that made them sad or tense. State-by-state statistical overviews of emotional well-being and physical wellbeing are provided in Figure 4 and Figure 5 respectively.

Figure 4. Emotional Well-Being Index by State

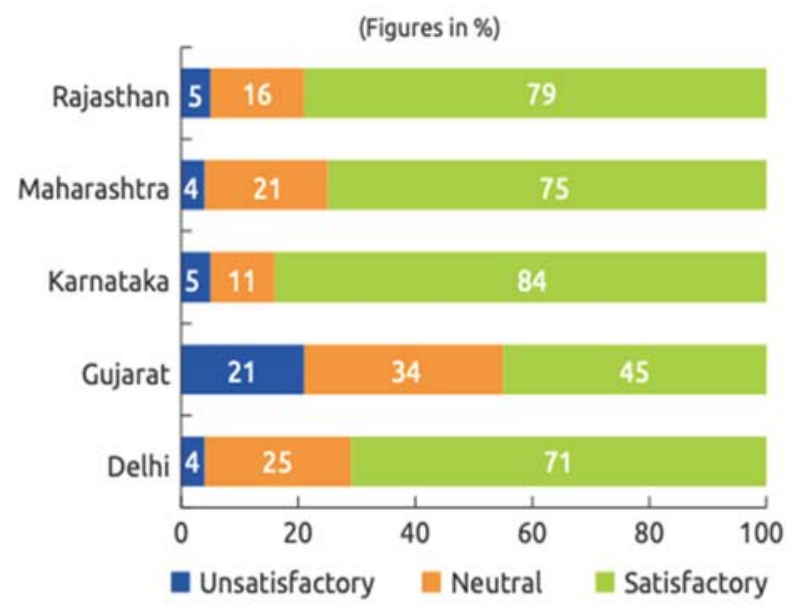

Figure 5. Physical Health Index by State

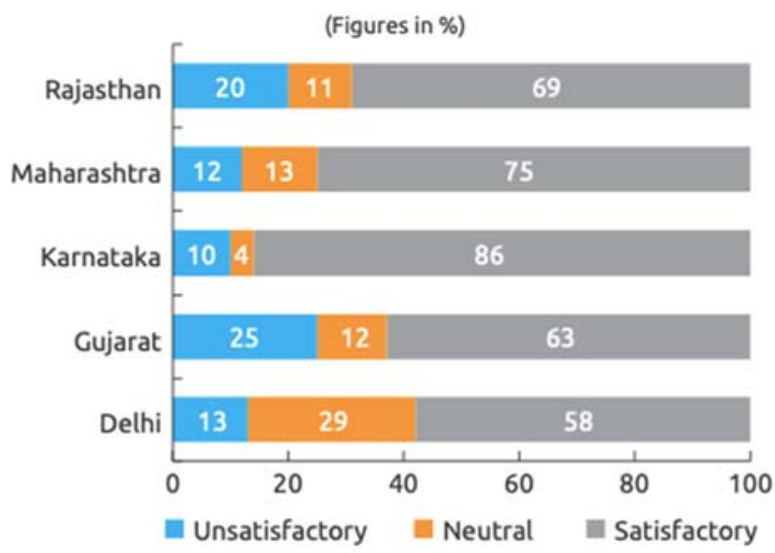


International Journal of Child, Youth and Family Studies (2020) 11(4.2): 160-187

As reported by one participant, a member of the Maharashtra Aftercare Association of Pune, "Poor mental health affects other aspects of adult life. Some CLs pick up jobs but leave them the next day" as they are not ready to cope with the new pressures of working life. We found that over $61 \%$ of the CLs faced recurring emotional distress and $22 \%$ of the CLs sought professional help. Our findings reprise those of Barn (2010), who noted that any challenges faced by CLs, such as unwillingness or inability to continue their education, failure to keep a job, difficulty in forging or maintaining relationships, and so on are rooted to some extent in their poor emotional health and lack of resilience.

Additionally, we found that mental health status did not differ between aftercare receivers and non-receivers, indicating a general lack of focus on building emotional resilience among CLs in order to increase their capacity to deal with stressful situations. Our study found that CLs face consistent stress and worry, mainly focused on their uncertainty about their futures. While a majority of the CLs face emotional distress, we also found that only a small proportion (about $22 \%$ ) seek professional help to address these issues. A female CL shared that she was concerned that she might be developing depressive symptoms as she is unable to sleep and prefers to isolate herself from her friends. In her words, "Lack of guidance and financial support has greatly impacted my mental and physical health." This therefore led us to the understanding that the focus of the stakeholders has to be rooted in providing adequate support for uplifting the emotional and physical well-being of CLs.

\section{Education and Vocational Skills}

The present educational status of the CLs - the level and quality of their educational and vocational skills - is the cumulative outcome of the education they received at the CCI and during aftercare, and has a considerable impact on different domains of their life. Internationally, for children and youth, it is common to change schools multiple times while in alternative care (Zetlin et al., 2004). However, these multiple changes result in frequently interrupted education, and have an impact on students' educational progress (Zetlin et al., 2004). In fact, students can lose 4 to 6 months of academic progress with every change of school. Given the poor academic performance that comes with frequent changes of school, coupled with improper guidance, children readily lose interest in school, start to find their studies a burden, and often forego secondary education altogether. Poor academic performance leads to negative long-term outcomes such as unemployment or low wages, making it difficult for the young people to earn a suitable livelihood (Torrico, 2010).

As previously noted by Torrico (2010), if educational and vocational skills have not been acquired before leaving care, integration into the post-care world becomes much more difficult. It is therefore of concern that our study found that $40 \%(n=174)$ of all CLs could not complete their schooling. What is even more worrisome is that $6 \%(n=24)$ of all CLs across the five states had not gone beyond primary education. Among the stakeholders participating in our study the understanding was that there were few options available for those who wanted to develop 
vocational skills, leaving little space for CLs to explore skills in accordance with their interests and aptitudes. Those who showed an academic inclination were limited by the paucity of financial support for higher education and skill development (Naccarto et al., 2010). The difficulty of finding funders either for academically average students or for expensive courses such as aeronautical engineering and medicine pushes CLs towards cheaper alternatives in their educational and vocational pursuits.

Of all the CLs across the five states, $21 \%$ did not receive their preferred type of education in the CCIs, which compromised their ability to achieve their full potential and explore life options accordingly. The education of CLs was further impacted during the transition to aftercare, as 34\% of CLs had to discontinue their education at that time. A stakeholder summarised the educational situation of CLs:

Children coming from vulnerable backgrounds do not know the importance of education and therefore they should be prepared at an early age, say 12 to 13 years onwards. They get admission in schools, but they are not able to adjust as the admission is not age appropriate. They often have to be in a class with small children. For example, there is a girl who is 19 and is in class 11 and the other one again 19, studying in class 10 and another has completed class 12 at 21 years of age. $^{3}$

As this quotation suggests, remedial education is a neglected aspect of aftercare. CLs would benefit from vocational training courses suited to their interests and abilities. Good quality education and vocational skills can be transformative in nature, but their lack can adversely impact not only the future financial independence but also the quality of life of CLs, and can further increase their vulnerability in the absence of parental figures and strong community ties and relationships (Valset, 2018).

\section{Financial Independence and Career}

Studies abroad have found that the financial status of an individual contributes importantly to not attaining aspirations and to quality of life (Fritz \& van Knippenberg, 2017). Financial independence is crucial for CLs if they are to live independent and comfortable lives once reintegrated into the community. Not only does lack of financial resources deprive them of basic amenities, but many CLs could fall through the cracks and disappear if left unsupported financially (Mares \& Jordan, 2012). Our study found that $48 \%$ of CLs did not have an independent source of income, that $93 \%$ of the earning CLs were in salaried jobs, and that $7 \%$ of CLs were self-employed. Overall, 38\% of the CLs were not able to cover their living expenses with their present income.

\footnotetext{
${ }^{3}$ In India, the usual age of child in 10th grade is 15 years, 11 th grade is 16 years, and 12 th grade is 17 years.
} 
The study further showed a gender disparity in the financial area: $45 \%$ of the female CLs had an unsatisfactory Financial index score compared to $33 \%$ of the male CLs. This shows that financial independence and security were far lower among female CLs than male CLs. Our findings show that CLs, especially females, generally have low financial literacy and little access to financial services, as well as an inability to manage financial crises. A gender disparity that limited female access to jobs and self-employment was also observed, primarily because of a lack of career guidance and absence of opportunities to acquire relevant employability skills during their stay in CCI or aftercare. More females (63\%) than males (36\%) reported not having an independent source of income even though a considerable percentage of the girls had completed class 12 (i.e., graduated from high school). Our findings echo those found in previous research; for example, see Bhargava and colleagues (2018).

\section{Identity and Legal Awareness}

Citizenship and identity are basic rights. They establish that an individual belongs to a nation and they allow access to the various services and benefits available to citizens; thus, they are important for the survival of an individual. Absence of legal documents of identity and citizenship can lead to confusion and exclusion from governance processes and to increased vulnerability (Karandikar \& Charegaonkar, 2019). Although legal literacy is an area that is often not considered a significant part of a CL's life, it is important for CLs to be aware of their legal rights and identity. Therefore, the study documented and analysed the CL's level of legal awareness and identity. Findings on this domain show that $55 \%$ of all CLs had not received any information regarding their legal rights and responsibilities during their stay in the CCI and only $33 \%$ of the CLs were aware of their right to receive aftercare under the JJ Act. Given the lack of availability of formal guidance, it may be a long struggle to achieve legal awareness for CLs but that is essential to ensure their integration as citizens of the state.

\section{Key Learnings}

Key learnings regarding the life of CLs in CCIs, and their transition out of care emerged from the study's findings. First, the child protection system (CCIs, CWCs, and DCPUs) is presently underprepared to handle transition, and thus the CLs are not well prepared for transitioning out of care at 18 years. Stakeholders - including CCI staff, CWCs, DCPUs, and aftercare providers have a limited conceptual understanding of what is involved when CLs transition out of care, are unclear about extending the concept of continuum of care through aftercare, and thus are impaired in their capacity to plan and implement aftercare. Besides this, the collected data from several indepth interviews showed that, within the child protection system, there is an absence of coordination and convergence with other systems such as health, education, and urban affairs.

Institutionalisation has an impact on the education and skills attained by CLs. Acquisition of independent living skills by CLs in CCI and in aftercare is low and is impacted by gender biases, and by the nature of the care provided at the CCI. Data from the interviews indicated that 
vocational skills were prioritised over higher education: the children were "pushed" towards it in an attempt to get settled in life during their limited time in care. The NGO-run CCIs have been seen to provide more skill training than government-run CCIs in various skill areas, demonstrating the possibility of better planning for skills as part of alternative care.

As our findings show, unprepared transitioning out of care has a negative impact on the emotional well-being of CLs, and there is a greater negative impact on the emotional well-being of female CLs than male CLs. Abrupt transitions lead to stressful situations as CLs struggle with finding accommodation and securing finances, and with matters relating to their physical, mental, and emotional well-being (Barn, 2010; Meade \& Mendes, 2014; Vacca, 2008). Many participants reported that, during the transition phase, they experienced symptoms of clinical depression, anxiety, stress, and even suicidal tendencies. Institutionalisation also has a strong impact on the adult social life of the CL in aftercare. In agreement with previous studies, as mentioned earlier, our findings show that children who are deprived of opportunities to develop stable and continuous attachment relationships due to their limited number of social relationships and poor quality of contact with their caregivers have difficulty with social relationships, and their ability to develop a support system for themselves is negatively impacted (Gunnar et al., 2000).

This study revealed conclusive trends on aftercare practices across the five states along with a glimpse of the existing diversity of aftercare practices in the states. The overall problems and challenges faced by CLs are quite similar across states, indicating that the overall policy provisions for aftercare need strengthening, and that there is a need for a robust machinery and human resources for delivery of aftercare services. The next section sets forth recommendations for policy and for implementation of aftercare.

\section{Recommendations}

Our literature review and our research established that lack of aftercare support for CLs hampers outcomes of adult life across the eight domains of the Sphere of Aftercare, whereas adequate support positively impacts outcomes. Our findings reinforce the interconnectedness of the different domains in the Sphere of Aftercare, and hence the need to establish a far more comprehensive aftercare programme than exists today.

First of all, the effective implementation of the existing policies and law would bring about a transformation in aftercare. Implementation of the JJ Rule 25, which mandates state governments to develop an aftercare programme with clarity on provisions of aftercare, is requisite.

Since practice is informed by the legislative framework with respect to the issue, it is imperative that the government makes changes in the policy and legislative framework governing aftercare. Specifically, CLs should be recognised as a vulnerable category under the National Youth Policy 2014 and National Policy on Skill Development and Entrepreneurship, 2015. 
International Journal of Child, Youth and Family Studies (2020) 11(4.2): 160-187

Moreover, certain changes should be made in the existing JJ Act 2015, JJ Model Rules 2016, and CPS to make aftercare more comprehensive, such as:

- the expansion of the definition of aftercare so that children who turn 18 and leave foster care, group foster care, and other alternative care options are also entitled to aftercare support;

- the introduction of mandatory transition planning for all children living in CCIs who are 14 years and older;

- the development and implementation of an individual aftercare plan for every CL; and

- the provision of at least one support centre for CLs in every district to provide such services as a range of development, settlement, and advancement choices, referrals, and access to information.

We also propose the establishment of a grievance redressal system for CLs, with a simultaneous increase in investment on aftercare. Budgetary norms under CPS should be increased from Rs. 2,000 per month per child to a range of Rs. 8,000 to Rs. 10,000 per youth per month.

Additionally, we believe that there is definitely a need to develop support centres for CLs need to ensure that adequate support is provided across all the domains of the Sphere of Aftercare. Starting with housing, states should promote the availability of a balanced mix of institutional and non-institutional housing supports for aftercare across districts in the state. For physical and mental health, the CLs should have easy access to health services, subsidised medical services, specialised counsellors for therapy, and health insurance via the PM-JAY (National Health Protection Scheme). With regard to educational and vocational skills, CLs should be provided with requisite support, guidance, and counselling to make academic and skill development choices based on their needs and aspirations. For this purpose, we recommend that there should be improved coordination among the Ministry of Skill Development and Entrepreneurship and the various schemes for skill development and education that are being developed at the state and national levels. Further, building an effective communication network to coordinate the provision of aftercare between various Ministries at the Union level, and Departments at the state and district levels, along with aftercare service providers such as CCIs, NGOs, community-based agencies, and corporations, is a critical step in developing the provision of aftercare services in the country. Regarding the legal awareness domain, the National Legal Aid Services Authority (NLASA) should ensure that adequate assistance is provided to CLs in legal documentation, legal awareness, and provision of legal aid. Furthermore, in order to secure financial independence and careers for the CLs, workshops should be organised where CLs can explore opportunities for training and career enhancement.

While conducting the research, it became evident that stakeholders across the child protection cadre had gaps in their conceptual understanding of aftercare as a continuum of care. A clear understanding of this concept should thus be imparted to the stakeholders - CWC members, 
DCPU staff, inspection committees, CCI caregivers, aftercare officers, and all the other child care functionaries. This could be accomplished by organising training for capacity building that fosters understanding of what constitutes the continuum of care.

An urgent recommendation is the strengthening of the voices of CLs themselves. For the CLs to develop the needed social support and interpersonal skills, we recommend that every CL have individual mentors to provide guidance in making life choices throughout transition and to be a stable source of emotional support. The collectivising of CLs into support groups and networks will provide another layer of support, where CLs can become contributors, and older CLs can mentor younger CLs. Technologies like MIS, social media, and text applications have the potential to organise CLs into a collective aimed at peer support and could be optimally used to benefit CLs. Models already exist at nascent stages. These should be supported and strengthened by state governments; successful models could then be replicated in other states.

\section{Conclusion}

In spite of legal regulations provided for the establishment and functioning of the CCIs and aftercare programmes, the goal - the smooth transition of the CL from a cocooned life in the CCI to life in the real world — seems far from being achieved. The study has shown that a comprehensive aftercare programme can have a transformative impact on the lives of CLs by reducing the struggles faced in transitioning out of care. It is important to understand the nature of the challenges faced by CLs in the domains of physical health, emotional wellbeing, social support and interpersonal skills, independent living skills, housing, identity and legal awareness, financial independence and career, and education and vocational skills. The financial allocation for aftercare is inadequate to provide comprehensive aftercare services to children who exit CCIs; therefore, states need to review their financial planning, funding allocations, and utilisation strategies for aftercare.

A programme of change under which existing laws are implemented effectively and harmonised with the recommendations suggested here will ensure the availability of aftercare services to youth exiting CCIs. Our hope is that this will lead to the CLs becoming true wards of the state, and bring the earliest possible end to the current situation, in which they are "nobody's responsibility". 
International Journal of Child, Youth and Family Studies (2020) 11(4.2): 160-187

\section{References}

Akister, J., Owens, M., \& Goodyer, I. M. (2010). Leaving care and mental health: Outcomes for children in out-of-home care during the transition to adulthood. Health Research Policy and Systems, 8, article 10. doi:10.1186/1478-4505-8-10

Andrea, N. (2018). Insights into structurally identical experiences of residential care alumni: The paradox of becoming autonomous in a residential care facility. International Journal of Child, Youth and Family Studies, 9(2): 61-85. doi:10.18357/ijcyfs92201818213

Atluri, N., Pogula, M., Chandrashekar, R., \& Gupta Ariely, S. (2018). Mental and emotional health needs of orphaned and separated youth in New Delhi, India during transition into adulthood. Institutionalised Children Explorations and Beyond, 5(2),188-207. $\underline{\text { doi:10.1177/2349301120180208 }}$

Barn, R. (2010). Care leavers and social capital: Understanding and negotiating racial and ethnic identity. Ethnic and Racial Studies, 33(5), 832-850. doi:10.1080/01419870903318896

Barth, R. P. (1990). On their own: The experiences of youth after foster care. Child and Adolescent Social Work Journal, 7(5), 419-440. doi:10.1007/BF00756380

Bhargava, R., Chandrashekhar, R., Kansal, S., \& Modi, K. (2018). Young adults transitioning from institutional care to independent living: The role of aftercare support and services. Institutionalised Children Explorations and Beyond, 5(2), 168-187. doi:10.1177/2349301120180207

Browne, E. (2017). Children in care institutions [K4D Helpdesk report]. Institute of Development Studies. https://www.ids.ac.uk/publications/children-in-care-institutions/

Center for Evidence-Based Management. (2014). Critical appraisal checklist for cross-sectional study [Resource document]. https://cebma.org/wp-content/uploads/Critical-AppraisalQuestions-for-a-Cross-Sectional-Study-July-2014-1.pdf

Dabir, N., Rego, A., \& Kapadia, K. (2011). Rainbow homes: Sunbursts in the lives of vulnerable girls. Tata Institute of Social Sciences.

Doucet, M. (2018). Relationships matter for youth 'aging out' of care [Research report]. McGill University School of Social Work. https://rcybc.ca/wpcontent/uploads/2019/04/relationships_matter_research_report_fall_2018_final_0.pdf

Dutta, S. (2017). Life after leaving care: Experiences of young Indian girls. Children and Youth Services Review, 73, 266-273. doi:10.1016/j.childyouth.2016.12.022 
International Journal of Child, Youth and Family Studies (2020) 11(4.2): 160-187

Everson-Hock, E. S., Jones, R., Guillaume, L., Clapton, J., Duenas, A., Goyder, E., Chilcott, J., Cooke, J., Payne, N., Sheppard, L, M., \& Swann, C. (2011). Supporting the transition of looked-after young people to independent living: A systematic review of interventions and adult outcomes. Child: Care, Health and Development, 37(6), 767-779. doi:10.1111/j.1365$\underline{2214.2011 .01287 . x}$

Fritz, C., \& van Knippenberg, D. (2017). Gender and leadership aspiration: The impact of worklife initiatives. Human Resource Management, 57(4), 855-868. doi:10.1002/hrm.21875

Gunnar, M. R., Bruce, J., \& Grotevant, H. D. (2000). International adoption of institutionally reared children: Research and policy. Development and Psychopathology, 12(4), 677-693. doi:10.1017/s0954579400004077

Gutterswijk, R. V., Kuiper, C. H. Z.., Lautan, N., Kunst, E. G., van der Horst, F. C. P., Stams, G. J. J. M., \& Prinzie, P. (2020). The outcome of non-residential youth care compared to residential youth care: A multilevel meta-analysis. Children and Youth Services Review. 113, 1-11. doi:10.1016/j.childyouth.2020.104950

Häggman-Laitila, A., Salokekkilä, P., \& Karki, S. 2019. Young people's preparedness for adult life and coping after foster care: A systematic review of perceptions and experiences in the transition period. Child Youth Care Forum, 48, 633-661. doi:10.1007/s10566-019-09499-4

Juvenile Justice (Care And Protection Of Children) Act (2015). The Gazette Of India. http://cara.nic.in/PDF/JJ\%20act\%202015.pdf

Juvenile Justice (Care and Protection of Children) Model Rules (2016). The Gazette Of India. http://cara.nic.in/PDF/english\%20model\%20rule.pdf

Karandikar, P., \& Charegaonkar, A. (2019). Aftercare for young adult orphans [Reinventing India: PIC policy paper \#13]. Pune International Centre. https://puneinternationalcentre.org/publication/aftercare-young-adult-orphans/

Legal Center for Foster Care and Education. (2008). Questions and answers: Credit transfer and school completion. American Bar Association and Casey Family Programs.

https://web.archive.org/web/20170827082931/https:/www.americanbar.org/content/dam/aba/ migrated/child/education/QA_2_Credits_FINAL.authcheckdam.pdf

Mares, A. S., \& Jordan, M. (2012). Federal aftercare programs for transition-aged youth. Children and Youth Services Review, 34(8), 1509-1518. doi:10.1016/j.childyouth.2012.04.007

Meade, S., \& Mendes, P. (2014). Interim evaluation report for the Berry Street pilot program 'Stand By Me'. Berry Street. https://aifs.gov.au/cfca/pacra/interim-evaluation-report-berrystreet-pilot-program-stand-me 
International Journal of Child, Youth and Family Studies (2020) 11(4.2): 160-187

Ministry of Skill Development and Entrepreneurship. (2015). National Policy on Skill Development and Entrepreneurship 2015. https:/www.msde.gov.in/reportsdocuments/policies/national-policy-skill-development-and-entrepreneurship-2015

Ministry of Women and Child Development. (2013). The National Policy for Children, 2013. The Gazette of India. https://wcd.nic.in/sites/default/files/npcenglish08072013 0.pdf

Ministry of Women and Child Development. (2014). Revised integrated child protection scheme (CPS): A centrally sponsored scheme of government-civil society partnership. https://cdn.s3waas.gov.in/s32a79ea27c279e471f4d180b08d62b00a/uploads/2018/03/2018031 $\underline{348 . p d f}$

Ministry of Women and Child Development. (2016). National Plan of Action for Children 2016. https:/wcd.nic.in/sites/default/files/National\%20Plan\%20of\%20Action\%202016.pdf

Ministry of Youth Affairs \& Sports. (2014). National Youth Policy 2014. https://yas.nic.in/sites/default/files/National-Youth-Policy-Document.pdf

Modi, K., Anbalagan, E., Shroff, R., \& Singhal, N. (2018). Improving child care in India through the development of the Questionnaire to Assess Needs of Children in Care (QANCC). Scottish Journal of Residential Child Care, 17(2), 1-25.

Modi, K., Nayar-Akhtar, M., Ariely, S., \& Gupta, D. (2016). Addressing challenges of transition from children's home to independence: Udayan Care's Udayan Ghars (Sunshine Children's Homes) \& aftercare programme. Scottish Journal of Residential Child Care, 15(1), 87-101.

Montgomery, P., Donkoh, C., \& Underhill, K. (2006). Independent living programs for young people leaving the care system: The state of the evidence. Children and Youth Services Review, 28(12), 1435-1448. doi:10.1016/j.childyouth.2006.03.002

Mori, S., Nishizawa, S., \& Kimura, A. (2018). Reconsidering recent developments in Japanese residential care and the road to FICE Japan. International Journal of Child, Youth and Family Studies. 9(1), 121-131. doi:10.18357/ijcyfs91201818123

Murray, S., \& Goddard, J. (2014). Life after growing up in care: Informing policy and practice through research. Australian Social Work, 67(1), 102-117. doi:10.1080/0312407X.2013.868010?journalCode=rasw20

Rutman, D., \& Hubberstey, C. (2016). Is anybody there? Informal supports accessed and sought by youth from foster care. Children and Youth Services Review, 63, 21-27. doi:10.1016/j.childyouth.2016.02.007

Udayan Care. (2017). Standards of care in child care institutions. Udayan Care \& UNICEF. https://www.udayancare.org/sites/default/files/Standards_of_Care.pdf 
International Journal of Child, Youth and Family Studies (2020) 11(4.2): 160-187

Stein, M. 2012. Young people leaving care: Supporting pathways to adulthood. Jessica Kingsley.

Storli, R., \& Hansen Sandseter, E. B. (2019). Children's play, well-being and involvement: How children play indoors and outdoors in Norwegian early childhood education and care institutions. International Journal of Play, 8(1), 65-78. doi:10.1080/21594937.2019.1580338

Torrico, R. (2010). Youth aging out of foster care: Supporting their transition into adulthood. Children, Youth \& Families Practice Update, July, 1-5. https://www.socialworkers.org/assets/secured/documents/practice/children/children families practice update7-2010.pdf

Trout, A. L., Hoffman, S., Huscroft-D’Angelo, J., Epstein, M. H., Duppong Hurley, K., \& Stevens, A. L. (2014). Youth and parent perceptions of aftercare supports at discharge from residential care. Child and Family Social Work, 19(3), 304-311. doi:10.1111/cfs.12003

Trout, A. L., Chmelka, M. B., Thompson, R. W., Epstein, M. H., Tyler, P., \& Pick, R. (2010). The departure status of youth from residential group care: Implications for aftercare. Journal of Child and Family Studies, 19(1), 67-78. doi:10.1007/s10826-009-9283-9

Udayan Care. (2019). Beyond 18: Leaving child care institutions - A study of aftercare practices in five States of India. Tata Trusts, Udayan Care, \& UNICEF. https://www.udayancare.org/research-and-publication/research-studies-and-papers

United Nations. (1989). Convention on the rights of the child. Treaty Series, 1577, 3. https://www.unicef.org/child-rights-convention/convention-text

United Nations General Assembly resolution 64/142 (UNGACC). (2009). Guidelines for the alternative care of children. https://undocs.org/en/A/RES/64/142

United Nations World Youth Report. (2020). Youth and the 2030 agenda for sustainable development. https://www.un.org/development/desa/youth/world-youth-report/wyr2018.html

Vacca, J. S. (2008). Foster children need more help after they reach the age of eighteen. Children and Youth Services Review, 30(5), 485-492. doi:10.1016/j.childyouth.2007.11.007

Valset, K. (2018). Investigating the link between school performance, aftercare and educational outcome among youth ageing out of foster care: A Norwegian nationwide longitudinal cohort study. Nordic Social Work Research, 8(1), 79-93. doi:10.1080/2156857X.2018.1457557

Villagrana, M., Guillen, C., Macedo, V., \& Lee, S. Y. (2017). Perceived self-stigma in the utilization of mental health services in foster care and post foster care among foster care alumni. Children and Youth Services Review, 85, 26-34.

doi:10.1016/j.childyouth.2017.10.040 